\title{
Antiplasmodial Activity of $p$-Substituted Benzyl Thiazinoquinone Derivatives and Their Potential against Parasitic Infections
}

\author{
Marcello Casertano ${ }^{1,2}\left(\mathbb{D}\right.$, Marialuisa Menna ${ }^{1,2} \oplus$, Caterina Fattorusso ${ }^{1,2}\left(\mathbb{D}\right.$, Nicoletta Basilico ${ }^{3}(\mathbb{D}$,

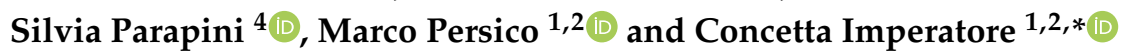 \\ 1 Department of Pharmacy, University of Naples “Federico II", Via D. Montesano 49, 80131 Napoli, Italy; \\ marcello.casertano@unina.it (M.C.); mlmenna@unina.it (M.M.); caterina.fattorusso@unina.it (C.F.); \\ marco.persico@unina.it (M.P.) \\ 2 Italian Malaria Network, Centro Interuniversitario di Ricerche Sulla Malaria (CIRM), Department of \\ Pharmacy, University of Naples “Federico II", Via D. Montesano 49, 80131 Napoli, Italy \\ 3 Dipartimento di Scienze Biomediche, Chirurgiche e Odontoiatriche, Università di Milano, Via Pascal 36, \\ 20133 Milan, Italy; nicoletta.basilico@unimi.it \\ 4 Dipartimento di Scienze Biomediche per la Salute, Università di Milano, Via Pascal 36, 20133 Milan, Italy; \\ silvia.parapini@unimi.it \\ * Correspondence: cimperat@unina.it; Tel.: +39-081678530
}

Received: 28 February 2020; Accepted: 25 March 2020; Published: 27 March 2020

\begin{abstract}
Malaria is a life-threatening disease and, what is more, the resistance to available antimalarial drugs is a recurring problem. The resistance of Plasmodium falciparum malaria parasites to previous generations of medicines has undermined malaria control efforts and reversed gains in child survival. This paper describes a continuation of our ongoing efforts to investigate the effects against Plasmodium falciparum strains and human microvascular endothelial cells (HMEC-1) of a series of methoxy $p$-benzyl-substituted thiazinoquinones designed starting from a pointed antimalarial lead candidate. The data obtained from the newly tested compounds expanded the structure-activity relationships (SARs) of the thiazinoquinone scaffold, indicating that antiplasmodial activity is not affected by the inductive effect but rather by the resonance effect of the introduced group at the para position of the benzyl substituent. Indeed, the current survey was based on the evaluation of antiparasitic usefulness as well as the selectivity on mammalian cells of the tested $p$-benzyl-substituted thiazinoquinones, upgrading the knowledge about the active thiazinoquinone scaffold.
\end{abstract}

Keywords: thiazinoquinones; Plasmodium falciparum; quinone-derived antimalarial agents; marine inspired compounds; cytotoxicity; antiparasitic agents

\section{Introduction}

The World Health Organization (WHO) considers human malaria as one of the major public health burdens, affecting primarily populations in tropical and subtropical countries [1,2]. Pregnant women and children are particularly vulnerable, but malaria infection is also a severe problem for travelers who come into endemic regions and for immunocompromised people. The decrease in the number of infected people, around 20 million fewer than 2010, is clear evidence of the great efforts made to fight this parasite. Nevertheless, in the timeframe 2015-2017, no significant progress has been recorded in term of a reduction of global malaria cases, with a remarkable percentage, approximatively $40 \%$, of the world's population still at risk of infection [2]. An additional setback is represented by multiparasitism; often, the malaria patient is co-infested by other parasite species, such as Schistosoma and Leishmania, 
classified as neglected tropical diseases (NTDs) due to the absence of efficient and consistent politics based on prevention and a consequent lack of investments by pharmaceutical industries [3].

In the frame of our studies aiming to explore new chemical entities that can be employed for the discovery of new drugs against malaria and other parasitic diseases [4-9], we have recently identified the bicyclic 1,1-dioxo-1,4-thiazine system fused to the quinone ring as a new scaffold active against $P$. falciparum and Schistosoma mansoni [4-9] exploiting natural marine metabolites as model compounds [10-14]. This work, based on the model of natural marine metabolites, aplidinone A and B (1 and 2), has yielded a chemical library of synthetic thiazinoquinones (3-22, Figure 1), which was funneled into a large screening for the search of antimalarial agents $[4,6,9]$. Many of these compounds have been demonstrated as effective antimalarials, but the research program has been focused on the methoxy-substituted compounds (6-12 and 16-22, Figure 1). Structure-activity relationship (SAR) studies evidenced that in this group of thiazinoquinones, only the compounds in which the methoxy substituent on the quinone ring is on the same side of the nitrogen of the thiazine ring (regioisomers B) were active, indicating this regiochemistry of the bicyclic moiety is a crucial requirement for the antiplasmodial activity $[4,6]$. Thus, the synthetic protocol designed for the production of methoxy thiazinoquinones with different alkyl side chains has been improved to make it as selective as possible in favor of the active regioisomer [4,6]. Among the tested thiazinoquinones, we have identified a lead candidate, compound 22, featuring a benzyl alkyl chain; it was found to be active in the range of low-micromolar concentrations against both chloroquine-sensitive (D10) and -resistant (W2) P. falciparum strains, and exhibited a good selectivity index (SI) on the tested mammalian cells $(>25)$. The key role of the thiazinoquinone heterocyclic moiety for the antiplasmodial activity was confirmed by the absence of activity showed by compound 23 , the corresponding quinone of 22 lacking the thiazine ring (Figure 1) [6]. The proposed antimalarial mechanism of action for $\mathbf{2 2}$ has been related to its capability to form a stable radical on the benzyl substituent that impairs the Plasmodium defense in the heme group detoxification pathway [6]. Definitively, overall, these results supported the eligibility of the thiazinoquinone as a new redox active scaffold, as an alternative to naphthoquinones [15], to be explored for its properties as a lead for the development of novel antimalarials.<smiles>COC1=C(C/C=C(\C)CCC=C(C)C)C(=O)C2=C(C1=O)S(=O)(=O)CCN2</smiles><smiles>CC(C)=CCC/C(C)=C/CC1=C(N)C(=O)C2=C(NCCS2(=O)=O)C1=O</smiles><smiles>COC1=C(Cc2ccccc2)C(=O)C=CC1=O</smiles>
23

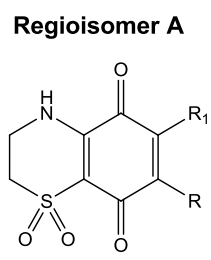

$3 \mathrm{R}=-\mathrm{NHCOCH}_{3} ; \mathrm{R}_{1}=-\mathrm{CH}_{2} \mathrm{CH}_{3}$ $4 \mathrm{R}=-\mathrm{NHCOCH}_{3} ; \mathrm{R}_{1}=-\left(\mathrm{CH}_{2}\right)_{4} \mathrm{CH}_{3}$ $5 \mathrm{R}=-\mathrm{NHCOCH}_{3} ; \mathrm{R}_{1}=-\left(\mathrm{CH}_{2}\right)_{10} \mathrm{CH}_{3}$ $6 \mathrm{R}=-\mathrm{OMe} ; \mathrm{R}_{1}=-\mathrm{CH}_{2} \mathrm{CH}_{3}$ $7 \mathrm{R}=-\mathrm{OMe} ; \mathrm{R}_{1}=-\mathrm{CH}_{2}\left(\mathrm{CH}_{2}\right)_{2} \mathrm{CH}_{3}$ $8 \mathrm{R}=-\mathrm{OMe} ; \mathrm{R}_{1}=-\left(\mathrm{CH}_{2}\right)_{7} \mathrm{CH}_{3}$ $9 \mathrm{R}=-\mathrm{OMe} ; \mathrm{R}_{1}=-\left(\mathrm{CH}_{2}\right)_{13} \mathrm{CH}_{3}$ $10 \mathrm{R}=-\mathrm{OMe} ; \mathrm{R}_{1}=-\mathrm{CH}_{2} \mathrm{CH}\left(\mathrm{CH}_{3}\right)_{2}$ $11 \mathrm{R}=-\mathrm{OMe} ; \mathrm{R}_{1}=-\mathrm{CH}_{2} \mathrm{C}_{6} \mathrm{H}_{11}$ $12 \mathrm{R}=-\mathrm{OMe} ; \mathrm{R}_{1}=-\mathrm{CH}_{2} \mathrm{C}_{6} \mathrm{H}_{5}$

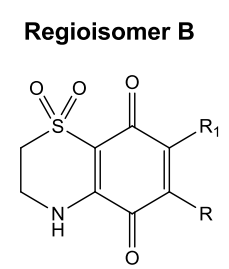

$13 \mathrm{R}=-\mathrm{NHCOCH}_{3} ; \mathrm{R}_{1}=-\mathrm{CH}_{2} \mathrm{CH}_{3}$ $14 \mathrm{R}=-\mathrm{NHCOCH}_{3} ; \mathrm{R}_{1}=-\left(\mathrm{CH}_{2}\right)_{4} \mathrm{CH}_{3}$ $15 \mathrm{R}=-\mathrm{NHCOCH}_{3} ; \mathrm{R}_{1}=-\left(\mathrm{CH}_{2}\right)_{10} \mathrm{CH}_{3}$ $16 \mathrm{R}=-\mathrm{OMe} ; \mathrm{R}_{1}=-\mathrm{CH}_{2} \mathrm{CH}_{3}$ $17 \mathrm{R}=-\mathrm{OMe} ; \mathrm{R}_{1}=-\mathrm{CH}_{2}\left(\mathrm{CH}_{2}\right)_{2} \mathrm{CH}_{3}$ $18 \mathrm{R}=-\mathrm{OMe} ; \mathrm{R}_{1}=-\left(\mathrm{CH}_{2}\right)_{7} \mathrm{CH}_{3}$ $19 \mathrm{R}=-\mathrm{OMe} ; \mathrm{R}_{1}=-\left(\mathrm{CH}_{2}\right)_{13} \mathrm{CH}_{3}$ $20 \mathrm{R}=-\mathrm{OMe} ; \mathrm{R}_{1}=-\mathrm{CH}_{2} \mathrm{CH}\left(\mathrm{CH}_{3}\right)_{2}$ $21 \mathrm{R}=-\mathrm{OMe} ; \mathrm{R}_{1}=-\mathrm{CH}_{2} \mathrm{C}_{6} \mathrm{H}_{11}$ $22 \mathrm{R}=-\mathrm{OMe} ; \mathrm{R}_{1}=-\mathrm{CH}_{2} \mathrm{C}_{6} \mathrm{H}_{5}$

Figure 1. Structures of the marine secondary metabolites aplidinones A (1) and B (2), and of the synthetic methoxy derivatives 3-23. 
Several antimalarial agents (e.g., artemisinin and its derivatives, chloroquine, mefloquine) are also effective against other parasites [16-18]. This prompted us to investigate the effects against S. mansoni of benzyl methoxy thiazinoquinone 22, of the quinone 23, and of the ad hoc synthesized $p$-substituted benzyl derivatives of 22, compounds 24-27 (Figure 2). This study was performed in the frame of a wider screening aiming to explore the potential of the methoxy thiazinoquinone system to search for novel multi-stage antischistosomal agents [8,9]. In particular, the influence on the anti-parasitic activity against $P$. falciparum D10 and W2 strains as well as mammalian cells of various electron-withdrawing and -donating groups $\left(-\mathrm{Cl},-\mathrm{CF}_{3},-\mathrm{OCH}_{3}\right.$, and $\left.-\mathrm{OCF}_{3}\right)$ at the para position of the benzyl side chain was evaluated.

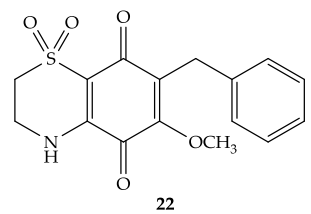

$$
\begin{aligned}
& \mathrm{IC}_{50} \text { (D10): } 0.60 \pm 0.21 \mu \mathrm{M} \\
& \mathrm{IC}_{50} \text { (W2): } 0.70 \pm 0.22 \mu \mathrm{M} \\
& \mathrm{IC}_{50} \text { (HMEC-1): } 17.6 \pm 1.4 \mu \mathrm{M} \\
& \mathrm{IC}_{50} \text { (NIH-3T3): } 88.6 \pm 7.7 \mu \mathrm{M}
\end{aligned}
$$<smiles>COC1=C(Cc2ccc(Cl)cc2)C(=O)C2=C(NCCS2(=O)=O)C1=O</smiles>

24

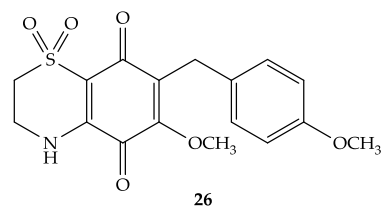<smiles>COC1=C(Cc2ccc(C(F)(F)F)cc2)C(=O)C2=C(NCCS2(=O)=O)C1=O</smiles>

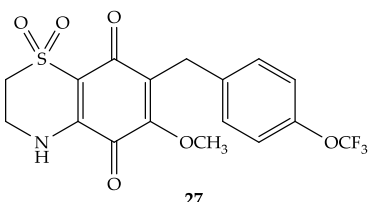

Figure 2. Structures of the $p$-substituted benzyl methoxy thiazinoquinones 24-27.

Thiazinoquinones 24-27, as well as the quinone $\mathbf{2 3}$, were first tested on schistosomula, the parasite larval stage; then, their effects on the viability of adult worm pairs and juvenile parasites, as well as on egg production and development, were evaluated. Interestingly, similar to what happens for the antiplasmodial effect, compounds $\mathbf{2 3}$ and all the regioisomeric A forms of methoxy thiazinoquinones were inactive [8]. All regioisomers B of $p$-substituted benzyl methoxy thiazinoquinones (compounds 24-27) were active on both parasite forms and eggs, with compounds $\mathbf{2 6}$ and $\mathbf{2 7}$ being the most potent compounds in the series. In the present communication, a brief upgrade on the pharmacological effects of compounds 24-27 is reported. Herein, we describe the not yet reported antiplasmodial behavior of compounds 24-27 on D10 and W2 P. falciparum strains in vitro and their cytotoxicity against human microvascular endothelial cells (HMEC-1). These results, integrated with those previously reported on the schistosomicidal activity of these compounds, highlight compound $\mathbf{2 6}$ as a potential hit active against both P. falciparum and S. mansoni.

\section{Results and Discussions}

Thiazinoquinones 24-27 (Figure 2) were prepared from the commercially available 1,2,4trimethoxybenzene as previously described [6,8]. In these compounds, the lead candidate 22 was modified by introducing various substituents (both electron-withdrawing and -donating groups) in the para position of the benzyl side chain. This chemical manipulation aimed to evaluate the possible effects on the antiparasitic activity and thus provide further evidence on the mode of action of thiazinoquinone derivatives. In our previously reported screening against S. mansoni, compounds 26 and 27, both bearing an oxygen atom directly linked to the benzyl side chain, showed a better overall activity profile against the different forms of the parasite (larval, adult and juvenile forms, eggs) when compared to 22 [8]. The higher activity of these two derivatives has been supposed to be related to the presence of the $\mathrm{H}$-bonds acceptor groups in the para position rather than the electronic effects on the aromatic ring of the substituents. Indeed, it has been supposed that these groups could possibly play a crucial role in the active thiazinoquinones, hypothesizing their membrane-transport proteins' exploitation to enter the parasite [8]. Likewise, the schistosomicidal drug of choice praziquantel (PZQ) has been proposed 
to compete with adenosine for its transport into the parasite by binding to the nucleoside transporter, and SARs performed on PZQ indicated that its substitution with an aromatic moiety is detrimental, unless it is a phenyl ring substituted in para by a H-bond donor/acceptor group $[8,19]$.

In order to evaluate the influence on the antimalarial activity of the substituents placed on the aromatic side chain of the lead candidate 22, compounds 24-27 were tested against chloroquine (CQ)-sensitive (D10) and -resistant (W2) strains of P. falciparum by using the parasite lactate dehydrogenase (pLDH) assay [20]. All the $p$-substituted benzyl derivatives of 22 retained activity and were effective as antiplasmodial in the micromolar range. Moreover, compounds 24-27 were evaluated for their cytotoxic effects against $\mathrm{HMEC}-1$ cells, too. The $\mathrm{IC}_{50}$ values on both P. falciparum strains and HMEC-1 cell line obtained for compounds 24-27, as well as those of the lead compound 22, are reported in Table 1. For each compound, the selectivity index (SI), namely the ratio between the $\mathrm{IC}_{50}$ values on the human cells and that on the parasite strains, was calculated; these data are reported in Table 1, alongside those calculated considering the $\mathrm{IC}_{50}$ values previously reported for compounds 22 and 24-27 on embryonic murine fibroblasts (NIH-3T3 cell line) [8]. It can be observed that, for the antiplasmodial activity, the $\mathrm{IC}_{50}$ values of compounds 24-27 are not significantly different from that of the lead candidate 22 and, actually, the activity of all thiazinoquinones was slightly decreased. The most remarkable lowering of the antiplasmodial activity was observed for compound 25 , which featured a substituent $\left(-\mathrm{CF}_{3}\right)$ with a strong electron-withdrawing inductive effect at the para position of the aromatic ring and no resonance effect. On the other hand, the groups introduced at the para position of the benzyl ring of compounds 24, 26, and 27 (Figure 2), which showed lower $\mathrm{IC}_{50}$ values than 25 (Table 1), although characterized in some cases by opposite inductive effects, share the presence of a lone pair, which can be conjugated to the aromatic ring. Noteworthy, the potency of compound 27 was higher against the chloroquine-resistant W2 strain than against the D10 strain (see Table 1), with an $\mathrm{IC}_{50}$ in the sub-micromolar concentration range $\left(\mathrm{IC}_{50}=0.81 \mu \mathrm{M}\right)$.

Table 1. $\mathrm{IC}_{50}$ in vitro values of compound 22 and $24-27$ on chloroquine (CQ) ${ }^{\mathrm{a}}$ sensible (D10) ${ }^{\mathrm{b}}$ and resistant (W2) ${ }^{b}$ strains of $P$. falciparum; cytotoxicity on HMEC-1 cell line ${ }^{\mathrm{c}}$ and relevant selectivity index (SI) ${ }^{\text {; }}$ SI on NIH-3T3 cell line ${ }^{\mathrm{e}}$.

\begin{tabular}{|c|c|c|c|c|c|c|c|}
\hline \multirow{2}{*}{ Compounds } & \multirow{2}{*}{$\begin{array}{c}\text { D10 IC } \mathrm{IC}_{50} \\
(\mu \mathrm{M})\end{array}$} & \multirow{2}{*}{$\begin{array}{c}\text { W2 } \text { IC }_{50} \\
(\mu \mathrm{M})\end{array}$} & \multirow{2}{*}{$\begin{array}{l}\text { HMEC-1 IC } \text { IC }_{50} \\
(\mu \mathrm{M})^{c}\end{array}$} & \multicolumn{2}{|c|}{$S^{d}{ }^{d}$} & \multicolumn{2}{|c|}{$\mathrm{SI}^{\mathrm{e}}$} \\
\hline & & & & D10 & W2 & D10 & W2 \\
\hline 22 & $0.60 \pm 0.21$ & $0.70 \pm 0.22$ & $17.6 \pm 1.4$ & 29.3 & 25.2 & 147.7 & 126.5 \\
\hline 24 & $1.63 \pm 0.35$ & $1.90 \pm 1.05$ & $8.51 \pm 0.76$ & 5.2 & 4.5 & 48.5 & 41.6 \\
\hline 25 & $5.06 \pm 1.68$ & $5.02 \pm 1.81$ & $20.4 \pm 1.60$ & 4.0 & 4.1 & 11.0 & 11.1 \\
\hline 26 & $1.21 \pm 0.20$ & $1.22 \pm 0.24$ & $17.9 \pm 1.10$ & 14.8 & 14.7 & $-f$ & $-f$ \\
\hline 27 & $1.12 \pm 0.40$ & $0.81 \pm 0.19$ & $3.59 \pm 0.72$ & 3.2 & 4.4 & 32.6 & 45.0 \\
\hline
\end{tabular}

${ }^{\mathrm{a}} \mathrm{CQ}$ as positive control: $\mathrm{D} 10 \mathrm{IC}_{50}(\mu \mathrm{M})=0.04 \pm 0.01 ; \mathrm{W} 2 \mathrm{IC}_{50}(\mu \mathrm{M})=0.54 \pm 0.28$; not cytotoxic. ${ }^{\mathrm{b}}$ Data are the mean \pm SD of three different experiments in duplicate. ${ }^{c}$ Camptothecin as positive control: $\mathrm{IC}_{50}(\mu \mathrm{M})=0.018 \pm 0.008$. $\mathrm{d}$ SI $=\mathrm{IC}_{50}$ HMEC-1/IC ${ }_{50} P$. falciparum strain. ${ }^{\mathrm{e}} \mathrm{SI}=\mathrm{IC}_{50} \mathrm{NIH}-3 \mathrm{~T} 3 / \mathrm{IC}_{50} P$. falciparum strain; cytotoxicity values on NIH-3T3 $(\mu \mathrm{M})$ of compounds 22 and $\mathbf{2 4 - 2 7}$ are reported in a previous work [8]. ${ }^{\mathrm{f}} \mathrm{SI}$ was not calculated since 26 is not active on NIH-3T3.

Definitively, as for the antiplasmodial activity, modification of the lead compound 22 did not provide a better candidate. However, this study demonstrated that $p-\mathrm{OCH}_{3}$ and $p-\mathrm{OCF}_{3}$ benzyl derivatives of 22, compounds 26 and 27, which have been highlighted as new promising schistosomicidal multi-stage hits, both possess good antiplasmodial activity in the micromolar range, with compound 27 being more active among the two on the CQ-resistant strain W2.

As for the toxic effects exerted by compounds $\mathbf{2 6}$ and 27 on the cell growth of HMEC-1 (Table 1), compound $27(\mathrm{cLog} \mathrm{D}=1.37)$ [8] was the most cytotoxic thiazinoquinone in the tested series with an $\mathrm{IC}_{50}$ value of $3.59 \mu \mathrm{M}$. On the contrary, the thiazinoquinone $26(\mathrm{cLogD}=0.33)$ [8] exhibited low cytotoxicity, comparable to that of the lead candidate $\mathbf{2 2}(\mathrm{cLogD}=0.41$, Table 1$)$. Furthermore, compound 26, when tested on the NIH-3T3 cell line, was completely ineffective $\left(\mathrm{IC}_{50}>100 \mu \mathrm{M}\right)$ [8]. 
Since it is known that a cLogD value $>1$ is needed for drugs' passive diffusion in mammalian cells [21], then, the toxicity against HMEC-1 and NIH-3T3 cell lines showed by 22, 26, and 27 may be related to their cLogD values (Table S1), in line with previously reported SARs $[6,8,9]$.

Evaluation of the calculated selectivity indexes (SIs) for the two different mammalian cell lines (see Table 1) of compounds 26 and 27 allowed a more proper assessment of their potential as antiparasitic agents. Even if their antiplasmodial and schistosomicidal potencies are comparable, compound $\mathbf{2 6}$ can be considered a better agent active against multiple parasites than $\mathbf{2 7}$ on the basis of its higher SI ratio on HMEC cells and its nontoxic effect on NIH-3T3 cells.

\section{Materials and Methods}

\subsection{General Experimental Procedures}

Commercial reagents and solvents: Sigma-Aldrich (Saint Louis, MO, USA) and Carlo Erba (Pomezia, Rome, Italy) whereas the anhydrous solvents were provided by Sigma-Aldrich or prepared by distillation according to standard procedures. Qualitative and semiquantitative TLC analyses: silica Gel 60 F254 (plates $5 \times 20,0.25 \mathrm{~mm}$ ) and silica Gel 60 F254 plates $(20 \times 20.2 \mathrm{~mm})$, respectively, Merck (Kenilworth, NJ, USA). Spots were revealed by a UV lamp, and then by spraying with $2 \mathrm{~N}$ sulfuric acid and heating at $120^{\circ} \mathrm{C}$. High-resolution electrospray ionization-mass spectrometry (ESI-MS (positive mode)) was performed on a Thermo LTQ Orbitrap XL mass spectrometer (Thermo-Fisher, San Josè, CA, USA) recording the spectra by infusion into the ESI source using $\mathrm{MeOH}$ as solvent.

NMR analysis was performed by a Bruker Avance Neo (Billerica, MA, USA) $700 \mathrm{MHz}$ (700 and $175 \mathrm{MHz}$ for ${ }^{1} \mathrm{H}$ and ${ }^{13} \mathrm{C} \mathrm{NMR}$, respectively). Chemical shifts were referenced to the residual solvent signal $\left(\mathrm{CDCl}_{3}: \delta_{\mathrm{H}}=7.26\right.$ and $\left.\delta_{\mathrm{C}}=77.0\right)$. Homonuclear ${ }^{1} \mathrm{H}$ connectivity was determined by correlation spectroscopy (COSY) experiments; one-bond heteronuclear ${ }^{1} \mathrm{H}-{ }^{13} \mathrm{C}$ connectivity by the heteronuclear single quantum coherence (HSQC) experiment; and two- and three-bond ${ }^{1} \mathrm{H}-{ }^{13} \mathrm{C}$ connectivity by gradient-HMBC experiments optimized for a ${ }^{2,3} \mathrm{~J}$ value of $8 \mathrm{~Hz}[22,23]$. High-performance liquid chromatography (HPLC) separations were performed both on a Shimadzu LC-10AT (Shimadzu, Milan, Italy) apparatus and on a Knauer K-501 apparatus (LabService Analytica s.r.l., Anzola dell'Emilia, Italy). Each instrument was equipped with a Knauer K-2301 RI detector.

\subsection{Synthesis of the Compounds 24-27}

The synthetic procedure needed to obtain the several thiazinoquinones 24-27 was already reported in our previous work. In particular, the protocol provided a good outcome for our interested compounds, confirming its interesting adaptability to different substrates [14].

Compound 24: orange powder; $t_{\mathrm{R}}=14 \mathrm{~min}$ (single peak). ${ }^{1} \mathrm{H} \mathrm{NMR}$ in $\mathrm{CDCl}_{3}$ and $\mathrm{HRESIMS}$ spectra are reported in Supporting Information (SI). HRESIMS: $m / z[\mathrm{M}+\mathrm{Na}]^{+}$calcd. for $\mathrm{C}_{16} \mathrm{H}_{14} \mathrm{ClNO}_{5} \mathrm{SNa}^{+}$: 390.0173, found: 390.0171.

Compound 25: orange powder; $t_{\mathrm{R}}=21 \mathrm{~min}$ (single peak). ${ }^{1} \mathrm{H} \mathrm{NMR}$ in $\mathrm{CDCl}_{3}$ and $\mathrm{HRESIMS}$ spectra are reported in Supporting Information (SI). HRESIMS: $m / z[\mathrm{M}+\mathrm{Na}]^{+}$calcd. for $\mathrm{C}_{17} \mathrm{H}_{14} \mathrm{~F}_{3} \mathrm{NO}_{5} \mathrm{SNa}^{+}$: 424.0437, found: 424.0438 .

Compound 26: dark orange powder; $t_{\mathrm{R}}=22 \mathrm{~min}$ (single peak). ${ }^{1} \mathrm{H}$ NMR in $\mathrm{CDCl}_{3}$ and $\mathrm{HRESIMS}$ spectra are reported in Supporting Information (SI). HRESIMS: $m / z[\mathrm{M}+\mathrm{H}]^{+}$calcd. for $\mathrm{C}_{17} \mathrm{H}_{18} \mathrm{NO}_{6} \mathrm{~S}^{+}$: 364.0849, found: 364.0845 .

Compound 27: orange powder; $t_{\mathrm{R}}=14 \mathrm{~min}$ (single peak). ${ }^{1} \mathrm{H} \mathrm{NMR}$ in $\mathrm{CDCl}_{3}$ and $\mathrm{HRESIMS}$ spectra are reported in Supporting Information (SI). HRESIMS: $m / z[\mathrm{M}+\mathrm{H}]^{+}$calcd. for $\mathrm{C}_{17} \mathrm{H}_{15} \mathrm{~F}_{3} \mathrm{NO}_{6} \mathrm{~S}^{+}$: 418.0555, found: 418.0556 .

\subsection{P. falciparum Cultures and Drug Susceptibility Assay}

All reagents were from Sigma Aldrich, Milan, Italy unless indicated otherwise. As reported in the literature [20], the chloroquine-sensitive (D10) and chloroquine-resistant (W2) strains of P. falciparum 
were maintained in vitro at 5\% hematocrit medium (constituted of human type Apositive red blood cells) in RPMI 1640 (EuroClone, Celbio, Italy) with the addition of 1\% AlbuMax (Invitrogen, Milan, Italy), $0.01 \%$ hypoxanthine, $20 \mu \mathrm{M}$ HEPES, and $2 \mu \mathrm{M}$ glutamine. The resulting cultures were incubated at $37^{\circ} \mathrm{C}$ in a mixture of standard gas with the following composition: $1 \% \mathrm{O}_{2}, 5 \% \mathrm{CO}_{2}$, and $94 \% \mathrm{~N}_{2}$. Drug susceptibility assay was required to solubilize the tested compounds in DMSO, and subsequently, diluted with the medium until the required concentration in order to have a final DMSO concentration less than 1\% that was not toxic for the parasites. Drugs were placed in 96 well flat-bottom microplates and a series of dilutions performed. Asynchronous cultures (parasitemia of $1-1.5 \%$; $1 \%$ final hematocrit) were aliquoted into the plates and incubated for $72 \mathrm{~h}$ at $37{ }^{\circ} \mathrm{C}$. The cultures were washed with PBS before the chemosensitivity assay while the parasite growth was determined spectrophotometrically (OD650) by measuring the parasite lactate dehydrogenase (pLDH) activity. These measurements were made according to the modified version of Makler's method both in control and drug-tested cultures [20]. Antiplasmodial activity is expressed as $50 \%$ inhibitory concentrations $\left(\mathrm{IC}_{50}\right)$, which means the dose of compounds necessary to inhibit cell growth by $50 \%$. Each $\mathrm{IC}_{50}$ value is the mean standard deviation of at least three separate experiments performed in duplicate.

\subsection{Cytotoxicity Assay}

The HMEC-1 cell line immortalized by SV 40 large T antigen43 was maintained in MCDB 131 medium (Invitrogen, Milan, Italy) supplemented with 10\% heat-inactivated fetal calf serum (HyClone, Celbio, Milan, Italy), $10 \mathrm{ng} / \mathrm{mL}$ of epidermal growth factor (Chemicon), $1 \mathrm{mg} / \mathrm{mL}$ of hydrocortisone, $2 \mu \mathrm{M}$ glutamine, $100 \mathrm{U} / \mathrm{mL}$ of penicillin, $100 \mathrm{mg} / \mathrm{mL}$ of streptomycin, and $20 \mu \mathrm{M}$ of Hepes buffer (EuroClone).

\section{Conclusions}

In this communication, our aim was to investigate the effects against $P$. falciparum strains and HMEC-1 cell line of a series of methoxy $p$-benzyl-substituted thiazinoquinones (24-27) designed from compound 22, earlier pointed out as an antimalarial lead candidate. For compounds 24-27, each modification on the benzyl ring linked to the quinone moiety did not enhance the antiplasmodial activity, which was decreased with respect to compound 22 but, in any case, preserved. In the series, it is worthy to note that the more compelling compounds were $\mathbf{2 6}$ and $\mathbf{2 7}$, which showed $\mathrm{IC}_{50}$ values against $P$. falciparum in the micromolar and sub-micromolar range. In summary, the results obtained expanded our SAR studies on substituted thiazinoquinones as antiparasitic agents, indicating that antiplasmodial activity is not affected by the inductive effect but rather by the (electron donating) resonance effect of the introduced substituent at the para position of the benzyl ring. The achieved data are an integral part of our ongoing investigation to identify new suitable antiparasitic agents whose therapeutic potential could be exploited in co-infection processes caused by more than one human parasite. Indeed, the current survey was based on the evaluation of antiparasitic usefulness as well as the selectivity on mammalian cells of the thiazinoquinones $\mathbf{2 4 - 2 7}$, hence upgrading the knowledge about the active thiazinoquinone scaffold.

Considering the overall obtained antiplasmodial effects, the reported properties against all stages of the blood-dwelling S. mansoni [8], and the interference on the mammalian cells' viability (HMEC-1 and NIH-3T3), we might define compound 26 as a new promising dual-acting antiparasitic agent since it showed itself as being superior among antiparasitic and antiproliferative effects. Finally, these studies corroborated the interesting potential of the bicyclic 1,1-dioxo-1,4-thiazine moiety as an active chemotype effective on more than one neglected parasite and, hence, able to vanquish the serious problem of the co-infection that is currently the cause of a high morbidity percentage in the most vulnerable countries worldwide.

Supplementary Materials: The following are available online at http://www.mdpi.com/1420-3049/25/7/1530/s1, Figure S1: HRESIMS spectrum of compound 24, Figure S2: ${ }^{1} \mathrm{H}$ NMR spectrum of compound 24 in $\mathrm{CDCl}_{3}$, Figure S3: HRESIMS spectrum of compound 25, Figure S4: ${ }^{1} \mathrm{H}$ NMR spectrum of compound 25 in $\mathrm{CDCl}_{3}$, 
Figure S5: HRESIMS spectrum of compound 26, Figure S6: ${ }^{1} \mathrm{H}$ NMR spectrum of compound 26 in $\mathrm{CDCl}_{3}$, Figure S7: HRESIMS spectrum of compound 27, Figure S8: ${ }^{1} \mathrm{H}$ NMR spectrum of compound 27 in $\mathrm{CDCl}_{3}, \mathrm{Table} \mathrm{S1}$ cLogD values of compounds 22 and 24-27.

Author Contributions: Conceptualization, M.C., M.M. and C.I.; Data curation, M.C., M.M., C.F., N.B., M.P. and C.I.; Formal analysis, M.C., S.P., M.P. and C.I.; Funding acquisition, M.M. and C.F.; Investigation, M.C. and C.I.; Methodology, M.C., M.M., C.F., N.B., S.P., M.P. and C.I.; Writing-original draft, M.C., M.M., C.F., N.B., M.P. and C.I.; Writing-review and editing, M.C., M.M., C.F., N.B., S.P., M.P. and C.I. All authors have read and agreed to the published version of the manuscript.

Funding: This research was funded by Ministero dell'Istruzione, dell'Università e della Ricerca (MIUR), PRIN Projects 20154JRJPP_004 and by a grant from Regione Campania-POR Campania FESR 2014/2020 “Combattere la resistenza tumorale: piattaforma integrata multidisciplinare per un approccio tecnologico innovativo alle oncoterapie-Campania Oncoterapie" (Project N. B61G18000470007).

Conflicts of Interest: The authors declare no conflict of interest.

\section{References}

1. WHO. World Malaria Report 2019. Available online: https://www.who.int/publications-detail/world-malariareport-2019 (accessed on 4 December 2019).

2. Murray, C.J.; Rosenfeld, L.C.; Lim, S.S.; Andrews, K.G.; Foreman, K.J.; Haring, D.; Fullman, N.; Naghavi, M.; Lozano, R.; Lopez, A.D. Global malaria mortality between 1980 and 2010: A systematic analysis. Lancet 2012, 379, 413-431. [CrossRef]

3. Steinmann, P.; Du, Z.W.; Utzinger, J.; Zhou, X.N. Multiparasitism: A neglected reality at global, regional and local scale. Adv. Parasit. 2010, 73, 21-50.

4. Imperatore, C.; Persico, M.; Aiello, A.; Luciano, P.; Guiso, M.; Sanasi, M.F.; Taramelli, D.; Parapini, S.; Cebrian-Torrejon, G.; Domenech-Carbo, A.; et al. Marine inspired antiplasmodial thiazinoquinones: Synthesis, computational studies and electrochemical assays. RSC Adv. 2015, 5, 70689-70702. [CrossRef]

5. Casertano, M.; Imperatore, C.; Luciano, P.; Aiello, A.; Putra, M.Y.; Gimmelli, R.; Ruberti, G.; Menna, M. Chemical Investigation of the Indonesian Tunicate Polycarpa aurata and Evaluation of the Effects Against Schistosoma mansoni of the Novel Alkaloids Polyaurines A and B. Mar. Drugs 2019, 17, 278. [CrossRef] [PubMed]

6. Imperatore, C.; Persico, M.; Senese, M.; Aiello, A.; Casertano, M.; Luciano, P.; Basilico, N.; Parapini, S.; Paladino, A.; Fattorusso, C.; et al. Exploring the antimalarial potential of the methoxy-thiazinoquinone scaffold: Identification of a new lead candidate. Bioorg. Chem. 2019, 85, 240-252. [CrossRef]

7. Imperatore, C.; Cimino, P.; Cebrián-Torrejón, G.; Persico, M.; Aiello, A.; Senese, M.; Fattorusso, C.; Menna, M.; Doménech-Carbó, A. Insight into the mechanism of action of marine cytotoxic thiazinoquinones. Mar. Drugs 2017, 15, 335. [CrossRef]

8. Gimmelli, R.; Persico, M.; Imperatore, C.; Saccoccia, F.; Guidi, A.; Casertano, M.; Luciano, P.; Pietrantoni, A.; Bertuccini, L.; Paladino, A.; et al. Thiazinoquinones as New Promising Multistage Schistosomicidal Compounds Impacting Schistosoma mansoni and Egg Viability. ACS Infect. Dis. 2020, 6, 124-137. [CrossRef]

9. Imperatore, C.; Gimmelli, R.; Persico, M.; Casertano, M.; Guidi, A.; Saccoccia, F.; Ruberti, G.; Luciano, P.; Aiello, A.; Parapini, S.; et al. Investigating the Antiparasitic Potential of the Marine Sesquiterpene Avarone, its reduced form Avarol, and the Novel Semisynthetic Thiazinoquinone analogue Thiazoavarone. Mar. Drugs 2020, 18, 112. [CrossRef]

10. Aiello, A.; Fattorusso, E.; Luciano, P.; Mangoni, A.; Menna, M. Isolation and structure determination of aplidinones A-C from the Mediterranean ascidian Aplidium conicum: A successful regiochemistry assignment by quantum mechanical ${ }^{13} \mathrm{C}$ NMR chemical shift calculations. Eur. J. Org. Chem. 2005, 5024-5030. [CrossRef]

11. Aiello, A.; Fattorusso, E.; Luciano, P.; Menna, M.; Calzado, M.A.; Muñoz, E.; Bonadies, F.; Guiso, M.; Sanasi, M.F.; Cocco, G.; et al. Synthesis of structurally simplified analogues of aplidinone A, a pro-apoptotic marine thiazinoquinone. Bioorg. Med. Chem. 2010, 18, 719-727. [CrossRef]

12. Imperatore, C.; Della Sala, G.; Casertano, M.; Luciano, P.; Aiello, A.; Laurenzana, I.; Piccoli, P.; Menna, M. In Vitro Antiproliferative Evaluation of Synthetic Meroterpenes Inspired by Marine Natural Products. Mar. Drugs 2019, 17, 684. [CrossRef] [PubMed]

13. Lam, C.F.C.; Pearce, A.N.; Tan, S.H.; Kaiser, M.; Copp, B.R. Discovery and evaluation of thiazinoquinones as anti-protozoal agents. Mar. Drugs 2013, 11, 3472-3499. [CrossRef] [PubMed] 
14. Davis, R.A.; Duffy, S.; Fletcher, S.; Avery, V.M.; Quinn, R.J. Thiaplakortones A-D: Antimalarial thiazine alkaloids from the australian marine sponge Plakortis lita. J. Org. Chem. 2013, 78, 9608-9613. [CrossRef] [PubMed]

15. Klotz, L.O.; Hou, X.; Jacob, C. 1,4-Naphthoquinones: From Oxidative Damage to Cellular and Inter-Cellular Signaling. Molecules 2014, 19, 14902-14918. [CrossRef]

16. Ashburn, T.T.; Thor, K.B. Drug repositioning: Identifying and developing new uses for existing drugs. Nat. Rev. Drug Discov. 2004, 3, 673-683. [CrossRef]

17. Patel, Y.S.; Mistry, N.; Mehra, S. Repurposing artemisinin as an anti-mycobacterial agent in synergy with rifampicin. Tubercolosis 2019, 115, 146-153. [CrossRef]

18. Keiser, J.; Utzinger, J. Antimalarials in the Treatment of Schistosomiasis. Curr. Pharm. Des. 2012, 18, 3531-3538. [CrossRef]

19. da Silva, V.B.R.; Campos, B.R.K.L.; de Oliveira, J.F.; Decout, J.L.; do Carmo Alves de Lima, M. Medicinal chemistry of antischistosomal drugs: Praziquantel and oxamniquine. Bioorg. Med. Chem. 2017, 25, 3259-3277. [CrossRef]

20. Makler, M.T.; Ries, J.M.; Williams, J.A.; Bancro, J.E.; Piper, R.C.; Gibbins, B.L.; Hinrichs, D.J. Parasite lactate dehydrogenase as an assay for Plasmodium falciparum drug sensitivity. Am. J. Trop. Med. Hyg. 1993, 48, 739-741. [CrossRef]

21. Lipinski, C.A.; Lombardo, F.; Dominy, B.W.; Feeney, P.J. Experimental and computational approaches to estimate solubility and permeability in drug discovery and development settings. Adv. Drug Deliv. Rev. 2001, 46, 3-26. [CrossRef]

22. Imperatore, C.; Luciano, P.; Aiello, A.; Vitalone, R.; Irace, C.; Santamaria, R.; Li, J.; Guo, Y.-W.; Menna, M. Structure and Configuration of Phosphoeleganin, a Protein Tyrosine Phosphatase 1B Inhibitor from the Mediterranean Ascidian Sidnyum elegans. J. Nat. Prod. 2016, 79, 1144-1148. [CrossRef] [PubMed]

23. Luciano, P.; Imperatore, C.; Senese, M.; Aiello, A.; Casertano, M.; Guo, Y.; Menna, M. Assignment of the Absolute Configuration of Phosphoeleganin via Synthesis of Model Compounds. J. Nat. Prod. 2017, 80, 2118-2123. [CrossRef] [PubMed]

Sample Availability: Samples of the compounds 24-27 are available from the authors.

(C) 2020 by the authors. Licensee MDPI, Basel, Switzerland. This article is an open access article distributed under the terms and conditions of the Creative Commons Attribution (CC BY) license (http://creativecommons.org/licenses/by/4.0/). 